\title{
The Effect of Organizational Characteristics on Inter-organizational Linkages - On the Basis of Elderly Employment Project Executing Organizations
}

\author{
Jayoung Cho and Sejeong Cheong
}

\begin{abstract}
This study aims to find out the effect of organizational characteristics of Elderly Employment Project executing nonprofit organizations on inter-organizational linkages. This research analyzed the 657 nonprofit organization staffs data from '2011 Elderly Employment Project Executing Organization Survey'. The major findings are as follows: First, the mean inter-organizational linkages score appears to be 3.808 out of 5.000 point maximum scale, which means 'good' level. Second, correlations among major variables are statistically significant. Third, formalization and communication are only statistically significant variables.
\end{abstract}

Index Terms-Elderly employment project, inter-organizational linkages, organizational characteristics, multiple linear regression analysis.

\section{INTRODUCTION}

Korea recently have faced with the issue of lack of mutual cooperation, overlapping and discontinuity of social services due to only focusing on quantitative expansion of social welfare organizations [1], resulting in increasing attention to the inter-organizational linkages among organization as one of alternatives.

In preceding studies [2]-[4], the inter-organizational linkages for an organization is reported to help not only overcome the social uncertainty and sudden change but also help survive of agency itself. Reference [2] mentioned that inter-organizational linkages among the nonprofit organizations can control or even reduce the environmental uncertainty [3]. According to [4], by cooperation among nonprofit organizations, there can be diversification of service types and supply mutual service, thus improve quality of service, reduce cost, and maximize economy of scale.

As researches disclosing effect of mutual cooperation between organizations arise, the research studies for factors affecting inter-organizational linkages have been also actively performed. One of the main factors affecting inter-organizational linkages is organizational characteristics The organizational characteristics explaining inter-organizational linkages have explained in variety of categories depending on researcher. Reference [5] stated centralization, formalization, innovation, communication, and complexity, while [6] explained with dedication to mutual cooperation, communication, strong leadership,

Manuscript received August 11, 2014; revised October 16, 2014

The authors are with the Graduate School of Social Welfare, Yonsei University, 50 Yonsei-ro, Seodaemun-gu, Seoul 120-749, South Korea (e-mail: jayoungcho@yonsei.ac.kr, sejeong@yonsei.ac.kr). understanding of cooperating organization, and supply of necessary resources to cooperating organization. Reference [7] argued a size of organization, stated purposes, organization principles, shape of structure, finance, management, and management structure, program and service scope of activity as organizational characteristic affecting inter-organizational linkages.

On the other hand, as Korea's society is aging, social burden such as sustenance allowance and medical expenses is increasing in large width. Accordingly, Korea is trying to decrease national burden and executing elderly employment policy to expand social activity of elders. Among the efforts, 'Elderly Employment Project' is its most recent representative policy. 'Elderly Employment Project' has its legal ground on $\ulcorner$ Elderly Welfare Act $\lrcorner$, providing jobs to elder who want work, resulting in forge of income along with social participation chance to prevent elderly problems as a poverty, illness, isolation from society and decrease social cost. Jobs provided from 'Elderly Employment Project' is 261,598 in 2013, which is 7 times more than that of 2004, when the project was first executed nation-wide.

The main characteristic of 'Elderly Employment Project' is that jobs are categorized as on public and on private area. For the public area, elders are provided of jobs and wages with government and public institutions employing the elder. On the other hand, for private area, nonprofit organization will provide jobs and wages with some support of working expenses from the government. However, jobs have been supplied by the government is over $77 \%$ of total jobs provided, and; moreover elders do tend to prefer jobs supplied by public institutions which is physically more comfortable.

However, practically need to expand the work of nonprofit organizations to the sustainability of the project because public institutions are more likely to have a limited amount of jobs. Also, a rapid increase in the aging of baby boomers requires an expansion of the variety of nonprofit organizations in the future. Due to this preference, attention is focused on securing various jobs with cooperation and connection among nonprofit organization. Despite the importance of cooperation between organizations participating in 'Elderly Employment Project', there are few studies dealing with inter-organizational linkages. Although such importance of cooperation between organizations participating in 'Elderly Employment Project' is increasing, the discussion related to this project is focusing on effectivity of project itself or satisfaction of participating elders, with almost no research on cooperation between organizations. 
For that purpose, this study is to find out the effect of centralization, formalization, communication, and complexity, which is four of five concepts proposed by [5], on inter-organizational linkages.

\section{METHODS}

\section{A. Research Model}

The research model as follows:

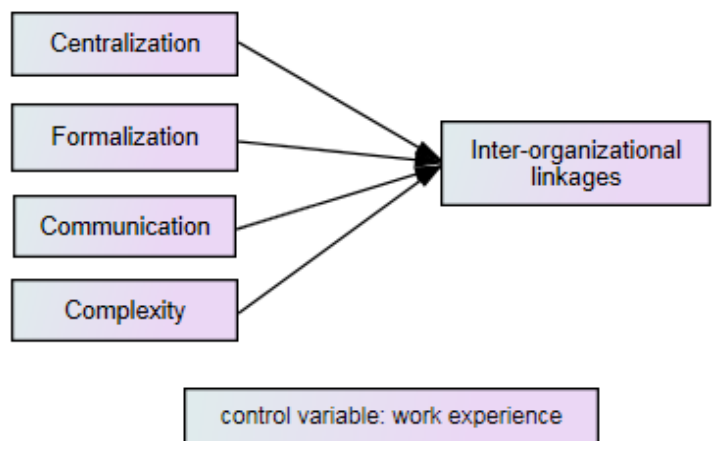

Fig. 1. Research model.

\section{B. Samples}

This research utilized the data from '2011 Elderly Employment Project Executing Organization Survey'. The investigation's subject of the study was 1,213 local governments and nonprofit organizations throughout the country which participates in the Elderly Employment Project, from which 777 organizations answered to the inquiries (657 nonprofit organizations and 120 local governments). This study extracted and analyzed 657 nonprofit organization data.

\section{Measure}

\section{1) Dependent variable}

\section{a) Inter-organizational linkages}

The inter-organizational linkages are measured by how well the inter-organizational linkages between the organizations related project is with 'very good, good, normal, bad, and very bad' criteria. Researcher has reverse questioned. The higher point means the better inter-organizational linkages.

\section{2) Independent variable}

\section{a) Centralization}

Centralization is measured by whether team leader system is operated while executing the Elderly Employment Project. Generally, the organization's centralization is meaning hierarchy in decision making process among organization [5]. As team leader exists in the project, there is one more steps to decision making process, therefore project being harder for the normal working level officials to have decision making authority. In this data, team leader exists is coded 1 and does not exist as 2 , both recorded as 1 and 0 by the researcher respectively.

\section{b) Formalization}

Formalization is the extent in which the task within the organization is standardized and can be measured by departmentalization of job descriptions [1]. Formalization has been measured by 4 point Likert criterion of 'very appropriate, appropriate, normal, not at all appropriate' for professional's division of works, responsible work amount, and responsible work contents. As researcher reverse questioned, higher the point values higher the work appropriateness, meaning higher the formalization is. Cronbach a coefficient is .902, showing high internal consistency reliability of criteria.

\section{c) Communication}

Communication is the internal exchange extent of the information with sharing the information and understanding correctly [8], measured by how much help the task education the manager received gave. The help extent of the task education is measured by 5 point criteria of 'not at all, somewhat not, normal, somewhat, and very yes' for the improvement of basic grounding, direct help to actual task, and useful skill and information supplement related to specific task. Higher the point values higher communication and more help task education's information gave. The reliability among inquires, Cronbach a coefficient, was .895 .

d) Complexity

Complexity is related to the internal specialization of organization's personal training's diversity and specific task amount [1]. In this study, the complexity is measured by how much manager perceives of the task specialization. Task specialization perception inquires asked if as a manager of Elderly Employment Project does the subject require necessary expertise or skills, measured by 'not at all, somewhat not, so-so, somewhat yes, and very much' of 5 point criteria. Higher the point values higher complexity and the task specialization perception is.

\section{3) Control variable}

\section{a) Work experience}

Work experience, a personal factor variable which was reported to effect the cooperation between organizations, was selected as control variable. The period engaged in the project generally affects work skill, also closely related to the organizational characteristic [9]. Work experience was measured by how much years the subject has engaged in the project.

\section{Data Analysis Methods}

To analyze socio-demographic characteristics, characters and correlations of inter-organizational linkage, centralization, formalization, community, complexity, work experience, we applied frequency, descriptive analysis, and correlation analysis with SPSS 22.0.

For the research goals, we applied Multiple Linear Regression analysis to find the organizational characteristics that effect on inter-organizational linkage.

\section{RESULTS}

\section{A. Socio-Demographic Characteristics}

The institutional types of the study subject were Korea Senior Citizen's Association (26.2\%), Seniors Welfare Community Center (22.5\%), Comprehensive Social Welfare 
Center (19.8), Senior Welfare Center (16.7\%), Senior Club (9.3\%), Other Institutions (5.3\%), and Rehabilitation Center for the Disabled $(0.2 \%)$.

The main role of the institution were periodical monitoring $(29.5 \%)$, and project evaluation(21.9\%), project settlement guidance in early stage(13.2\%), job training (11.1\%), vitalization of the cooperation system between organizations(10.4\%), project advertising(7.6\%), and extra support for the weak program $(6.2 \%)$.

TABLE I: SOCIO-DEMOGRAPHICS OF RESPONDENTS $(N=657)$

\begin{tabular}{llll}
\hline \hline Variables & Classification & Frequency & Ratio (\%) \\
\hline & $\begin{array}{l}\text { Korea Senior Citizen's } \\
\text { Association }\end{array}$ & 172 & 26.2 \\
& $\begin{array}{l}\text { Seniors Welfare } \\
\text { Community Center }\end{array}$ & 148 & 22.5 \\
Institutional & $\begin{array}{l}\text { Comprehensive Social } \\
\text { Type }\end{array}$ & 130 & 19.8 \\
& $\begin{array}{l}\text { Welfare Center } \\
\text { Senior Welfare Center }\end{array}$ & 110 & 16.7 \\
& $\begin{array}{l}\text { Other Institutions } \\
\text { Rehabilitation Center for } \\
\text { the Disabled }\end{array}$ & 1 & 5.3 \\
& $\begin{array}{l}\text { Periodical monitoring } \\
\text { Project evaluation }\end{array}$ & 194 & 0.2 \\
& $\begin{array}{l}\text { Project settlement } \\
\text { guidance in early stage }\end{array}$ & 87 & 21.9 \\
Main Role of & $\begin{array}{l}\text { Job training } \\
\text { Vitalization of }\end{array}$ & 73 & 13.2 \\
& $\begin{array}{l}\text { cooperation system } \\
\text { Project advertising } \\
\text { Extra support for the } \\
\text { weak program }\end{array}$ & 68 & 11.1 \\
\hline \hline
\end{tabular}

\section{B. Descriptive Analysis of Main Variables}

Main variable's descriptive statistics are shown in Table II.

TABLE II: DESCRIPTIVE STATISTICS OF MAIN VARIABLES

\begin{tabular}{|c|c|c|c|c|}
\hline Variables & Min & Max & Mean & S.E. \\
\hline $\begin{array}{l}\text { Inter-organizational } \\
\text { linkages }\end{array}$ & 1.000 & 5.000 & 3.808 & 0.759 \\
\hline Centralization & 1.000 & 5.000 & 4.085 & 0.848 \\
\hline Formalization & 1.000 & 5.000 & 3.887 & 0.754 \\
\hline Communication & 1.000 & 5.000 & 3.553 & 0.715 \\
\hline Complexity & 0.000 & 1.000 & 0.677 & 0.468 \\
\hline
\end{tabular}

\section{Correlation Analysis}

To verify the causal relationship set in the study, every correlation analyzed among the used inserted variables, showing statistically significant correlations among almost every variables as shown in Table III.

\section{Factors Effects on Inter-Organizational Linkages}

The main purpose of the study was to analyze the effect organizational characteristics has on the inter-organizational linkages. To do so, Multiple Linear Regression was executed.

In regression analysis of model, multicollinearity may occur. Therefore VIF (Variance Inflation Factor) was measured, resulting in no multicollinearity as VIF were from 1.014 to 1.068 .

The research model was statistically significant. For the independent variables, formalization $(\beta=.147, p<.01)$ and communication $(\beta=.120, p<.05)$ were only statistically significant variables. In other words, the task is more appropriately organized, and the perceived task education is more helped, more the inter-organizational linkages is done.

TABLE III: CORRELATION ANALYSIS

\begin{tabular}{|c|c|c|c|c|c|c|}
\hline Variables & (1) & (2) & (3) & (4) & (5) & (6) \\
\hline (1) & 1 & & & & & \\
\hline (2) & $.083^{*}$ & 1 & & & & \\
\hline (3) & $.205^{* *}$ & $.093 *$ & 1 & & & \\
\hline (4) & $.159 * *$ & .047 & $.188^{* * *}$ & 1 & & \\
\hline (5) & $.080 *$ & $.135^{* *}$ & .025 & .075 & 1 & \\
\hline (6) & $.102^{* * *}$ & $.083 *$ & .034 & .061 & .041 & 1 \\
\hline \multicolumn{7}{|c|}{$p^{*}<.05, p^{* *<} .01$} \\
\hline $\begin{array}{l}\text { (1) Inter-org } \\
\text { (4) Commu }\end{array}$ & $\begin{array}{l}\text { nizationa } \\
\text { cation (5) }\end{array}$ & $\begin{array}{l}\text { linka } \\
\text { mplex }\end{array}$ & $\begin{array}{r}\text { (2) } \\
\text { (6) Work }\end{array}$ & traliz & & malization \\
\hline
\end{tabular}

TABLE IV: MULTIPLE LINEAR REGRESSION

\begin{tabular}{|c|c|c|c|c|c|}
\hline \multicolumn{2}{|l|}{ Variables } & B & S.E & $\beta$ & Sig. \\
\hline $\begin{array}{l}\text { Control } \\
\text { variable }\end{array}$ & $\begin{array}{l}\text { Work } \\
\text { experience }\end{array}$ & .017 & .017 & .049 & .310 \\
\hline \multirow{4}{*}{$\begin{array}{l}\text { Independent } \\
\text { variable }\end{array}$} & Centralization & .079 & .087 & .044 & .363 \\
\hline & Formalization & .156 & .052 & .147 & $.003 * *$ \\
\hline & Communication & .127 & .052 & .120 & $.015^{*}$ \\
\hline & Complexity & .065 & .046 & .067 & .164 \\
\hline \multicolumn{2}{|c|}{$\mathrm{R}^{2}$} & \multicolumn{4}{|c|}{.243} \\
\hline \multicolumn{2}{|c|}{ Adjusted $\mathrm{R}^{2}$} & \multicolumn{4}{|c|}{.059} \\
\hline \multicolumn{2}{|r|}{$\mathrm{F}$} & \multicolumn{4}{|c|}{$5.214 * * *$} \\
\hline
\end{tabular}

\section{CONClusion}

This study is do empirical analysis of organizational characteristics effect on inter-organizational linkage based on the importance of organizations participating in Elderly Employment Project cooperating with related organization. From this study, the organizational characteristics which can promote Elderly Employment Project related organization's cooperation, which was non-existent before, were understood.

Given our data, we found that the organizational characteristic factor affecting related organization cooperation is formalization and communication. Formalization and communication help extent has statistically significant effect on inter-organizational linkages. On the other hand, centralization and complexity does not have statistically significant effect on inter-organizational linkages.

Based on our findings, we suggest three to promote inter-organizational linkages.

First, there is need to standardize the appropriate task content for various nonprofit organizations executing Elderly Employment Project. Results showing that division of labor structure, responsible task amount, or task content has statistically significant effect on the Elderly Employment Project's inter-organizational linkages turns up in all of the nonprofit organizations. However, as structure, size, or type of the organization varies, the task performance may vary. For example, the importance of the same project executed by senior welfare center and rehabilitation center for the 
disabled differs resulting in difference in the deployment of personnel or skillfulness. Therefore, regardless of the personnel type, there need to be a standardized job description developed and supplied.

Second, since task education has statistically significant effect on the inter-organizational linkages, there is need for the elaboration of task education. Currently the task education that Elderly Employment Project working level officials receive is task education, knowledge education, and refresher training, each of them required to gain knowledge and skill required for the task execution. However, the subject of education is various and type of education received varies depending on organization. For these reasons, continuous task education and refresher training should be elaborately formed and standardized to increase the specialty of the working level officials.

Finally, as a result of study, centralization and complexity does not have statistically significant effect on the inter-organizational linkages. Such result shows that centralization and complexity does indeed have no effect on the Elderly Employment Project inter-organizational linkages. Due to the limit of secondary data uses and measurement of centralization with existence of team leader management and measurement of complexity with task specialization perception, there might be chance that with different variables selected to represent centralization and complexity, the result might differ. In future research, the inter-organizational linkages extent or variables representing organizational characteristics should be formed in several levels, resulting in undertone of the integrated level.

\section{REFERENCES}

[1] J. S. Choi, Y. S. Kang, S. A. Choi, and S. M. Choi, "A study of the impact of organizational characteristics on collaboration among multi-purposed community social welfare centers," Journal of Korean Social Welfare Administration., vol. 6, pp. 87-112, 2003.

[2] P. M. Blau, Exchange and Power in Social Life, New York: Wiley, 1964.

[3] G. W. McGee, M. D. Fottler, R. M. Shewchuk, and C. W. Giardina, "Corporate structure and administrators' job stress: The case of nursing homes," Health Services Management Research, vol. 5, no. 1, pp. $54-65,1992$.
[4] B. B. Jr. Longest, "Interorganizational linkages in the health sector," Health Care Manage Review, winter, pp. 17-24, 1990.

[5] G. E. Klonglan, R. D. Warren, J. M. Winkelpleck, and S. K. Paulson, "Interorganizational measurement in the social service sector: differences by hierarchical level," Administrative Science Quarterly, vol. 21, pp. 675-687, 1976

[6] L. J. Johnson, D. Zorn, K. Y. B. Tam, M. Lamontagne, and S. A. Johnson, "Stakeholders' views of factors that impact successful interagency collaboration," Exceptional Children, vol. 69, no. 2, pp. 195-209, 2003.

[7] H. S. Zuckerman, and T. A. D'Aunno, "Hospital alliances: cooperative strategy in a competitive environment," Health Care Manage Review, vol. 15, no. 2, pp. 21-30. 1990

[8] K. T. Sung, Social Welfare Administration, Bobmunsa, 1993.

[9] J. Y. Kim and S. K. Park, "The study on factors affecting inter-agency coordination in family violence," Korean Journal of Social Welfare, vol. 47, no. 11, pp. 107-147, 2001.

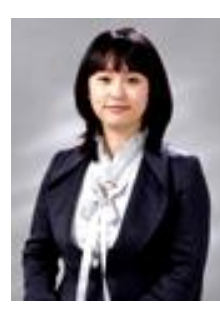

Jayoung Cho was born in Seoul, Korea on April 23, 1986. She received her master's degree in social welfare major at Yonsei Graduate School of Social Welfare, Seoul, South Korea in 2010. Jayoung Cho has 1 st degree (advanced level) nursing teacher certificate and 1st degree (advanced level) social worker certificate. She worked at Korean women's Development Institute as a researcher from March 2012 to December, 2012. From August 1st, 2010 to February 28th, 2012, she worked at child fund Korea. From May, 2009 to October, 2009, she worked as research assistant for "Development research for improvement plan and development pattern of senior housing." From September, 2009 to November, 2009, she worked as a research assistant for "Research for performance analysis and improvement plan of crisis household case management project." Now she works as a researcher for project for the specific local government.

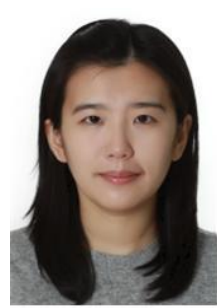

Sejeong Cheong was born on November 6, 1980, Korea. She completed her master degree of social welfare at Yonsei University, Seoul, South Korea. Sejeong Cheong's MSW was focused on social service delivery system and inter-organizational networks. She worked as a medical social worker as well as a researcher at the Korea Institute for Health and Social Affairs (KIHASA) on projects dealing with policy evaluation, social service design, and child welfare policy. She is presently studying as a $\mathrm{PhD}$ student in social work at Yonsei University, Korea. 